\title{
Human exposure against particles: the indoor-outdoor problem
}

\author{
U. Franck ${ }^{1}$, T. Tuch ${ }^{1,3}$, M. Manjarrez ${ }^{1}$, A. Wiedensohler ${ }^{3}$ \\ \& O. Herbarth ${ }^{1,2}$ \\ ${ }^{I}$ Department of Human Exposure Research \& Epidemiology, \\ Helmholtz Centre for Environmental Research - UFZ, Germany \\ ${ }^{2}$ Environmental Medicine \& Environmental Hygiene, \\ Faculty of Medicine, University of Leipzig, Germany \\ ${ }^{3}$ Leibniz-Institute for Tropospheric Research, Leipzig, Germany
}

\begin{abstract}
Airborne particles seem to be associated with health effects. The main question is what kind of particles (ultrafine, fine - PM2.5 or PM10) cause these adverse health effects. Linked with this question is the problem of exposure pattern and/or exposure scenarios and what is the contribution to the doses coming from outdoor and indoor exposure. In urban areas, ultrafine particles primarily originate from traffic. The influence of traffic on outdoor and indoor concentrations is therefore of special interest. Within epidemiological studies the exposure situation is usually characterized using outdoor particle concentrations, despite people spending most of their time indoors. The aim of the following study was to elucidate how indoor particle size distributions correlate with outdoor concentrations in the absence of significant indoor sources. The outdoor and indoor particle size distributions were measured with scanning and differential mobility particle analyzer systems. In absence of major indoor sources total indoor particle number concentrations were always lower than outdoor concentrations. Obviously the indoor environment is generally shielded against outdoor particulates. The indoor size distributions of particles are different from outdoor ones: the concentrations of very fine particles are decreased significantly and the concentration maxima are shifted to larger diameters with respect to outdoor particle sizes. Furthermore a time lag exists in the correlation between outdoor and indoor number concentrations. Outdoor particle concentrations contribute considerably to indoor concentrations. Therefore, in the absence of actual indoor measurements, outdoor particle size distributions can be used in epidemiological investigations as a surrogate for actual indoor particle concentrations. To assess the resulting particle burden for humans, a suitably weighted average emphasizing indoor aerosol particles must be used. To classify the health effects of particles of different diameters, different reductions of particle number concentrations depending on the particle sizes must be taken into account if indoor concentrations cannot be measured and outdoor concentrations are used in place of indoor measurements.
\end{abstract}

Keywords: particles, indoor, outdoor, health relevance. 


\section{Introduction}

Within epidemiological studies the exposure assessment is a basic step. This paper is devoted to some remarks to a rather new research topic in environmental hygiene and exposure research, the problem of outdoor to indoor relationships for submicrometer and ultrafine particles in ambient air.

It is now generally accepted that airborne particles may cause illness but the available data does not permit the derivation of specific guidelines for particles significantly smaller than $2.5 \mu \mathrm{m}$ in diameter. Because airborne particles do not constitute a uniform population, various measures for particulate air pollution have been investigated in epidemiological studies, the main ones being TSP (Total Suspended Particulate matter), PM10 and recently PM2.5 (Particle Mass concentration of particles smaller than 10 or $2.5 \mu \mathrm{m}$ in diameter; Phalen [1], Schwartz et al. [2], Murphy et al. [3], Pope et al. [4], Schwartz and Naes [5]). Nevertheless, the ill-health effects of PM2.5 have also been discussed (Gamble [6], Murphy et al. [3], Pekkanen, et al. [7], Tiittanen et al. [8]).

There is a simple reason to restrict epidemiological studies to particles which are smaller than 10 micrometer in aerodynamic diameter: very large particles are not inhalable and respirable. Therefore they cause no internal burden. Particles smaller than $10 \mu \mathrm{m}$ in diameter are on the other hand inhaled and deposited in the upper airways and the lungs. Three basic size dependent mechanisms determine efficiency and the location of particle deposition in the lungs:

Some findings suggest that particle fractions smaller than PM2.5 may be of great importance for adverse effects (Tsai et al. [9], Dreher et al. [10], Peters et al. [11], Pekkanen et al. [7], Oberdörster et al. [12]). Recently, special attention has been paid to submicron and ultrafine particles (smaller than $1 \mu \mathrm{m}$ ).

Principally, there are some simple arguments for paying special attention to particles $(<1 \mu \mathrm{m})$ and especially to ultrafine particles:

- $\quad$ Sub-micrometer and ultrafine particles may reach the deepest regions of the human respiratory system.

- $\quad$ Clearance mechanisms which remove inhaled particles for the lungs do not work as effectively for ultrafine particles as for larger particles.

- Compared to the mass concentrations which decreased dramatically within the last decades the number concentrations are still high or tend to increase.

- Urban traffic is a main source of these particles and urban traffic volume is increasing.

- Chemical composition of submicron and ultrafine particles may differ from larger ones because these particles originate from different sources.

Up to now most evidence for effects of these particles is based on laboratory studies (Osier and Oberdörster [13], Churg et al. [14], Murphy et al. [3], Li et al. [15], Lundborg et al. [16], Stone et al. [17], etc.). Only few epidemiological studies have paid special attention to the ill-health effects of such particles (Peters et al. [11], Pekkanen et al. [7], Wichmann et al. [18]). These studies 
usually use outdoor particle concentrations and size distributions measured at one site in the city which is regarded as typical for the city. But number concentrations of particles originating from traffic differ significantly within one city (Tuch et al. [19]).

And there is an additional important fact determining the human exposure to airborne pollutants: At least in most parts of Europe people spend most of their time indoors.

Unfortunately, epidemiological studies in the field of submicron and ultrafine particles are typically restricted to measurements of outdoor particle concentrations because detailed size-resolved indoor measurements in the homes of the study population are both time consuming and expensive. Detailed knowledge of ratios and correlation between indoor and outdoor particle size distributions is therefore needed to improve the quality of exposure assessment in such studies. Here we investigated how indoor particle size distributions of submicron and ultrafine particles correspond to the outdoor concentrations in the absence of significant indoor sources.

\section{Material and methods}

Measurements were carried out in different buildings and rooms in different floors on the institute campus. This site is an urban background site. We also included a site which is representative for typical traffic pollution in a city centre (Voigtländer et al. [20]).

Measurements of particle size distributions have been carried out between summer 1999 and summer 2004. Two different differential/scanning mobility particle sizer systems measured particle size distributions of particles between $\sim 15 \mathrm{~nm}$ and $\sim 800 \mathrm{~nm}$ indoors and outdoors simultaneously (TSI 3936L10, TSI, St.Paul, MN). Outdoor particle size distributions were measured by a custom made twin differential mobility particle sizer (Birmili et al. [21]). The comparability of both systems was verified by parallel outdoor measurements.

The indoor system was installed in an unoccupied apartment on the second floor of the typical European multi family townhouse with the windows and doors closed and without active ventilation (Franck et al. [22]). To minimize the effect of indoor sources (Chao et al. [23]) during the experiments, the level of human activity was kept low. The dwelling has modern, tightly closing windows. The air change rate was estimated judging by the type of windows and the literature to be in the order of 0.2-0.4 h-1 (Reinmuth [24], Krooß et al. [25], Ihle [26], Chao and Tung [27], Koponen et al. [28]). The theoretical rate was calculated using the length of the joints of windows and door to be $0.31 \mathrm{~h}-1 / 0.33$ h-1, respectively (DIN 4701). Additional measurements using SF6 as tracer gas yielded a mean rate of $0.16 / \mathrm{h}-1$ (for method cf. Lohmeyer [29]). The same measuring conditions were used for indoor measurements at the campus site.

Outdoor measurements from a street (Tuch et. al. [30]) and from a measurement station approx. $2 \mathrm{~km}$ (linear distance) away (campus, IfT) were used as outdoor reference data. The outdoor system sampled from a commercially available PM10 inlet mounted $5 \mathrm{~m}$ above the ground at a distance 
of $1 \mathrm{~m}$ from the wall of the building. The identical instrument at the measurement station site sampled from an identical inlet mounted on the roof of the institute building (height $13 \mathrm{~m}$ above the ground).

\section{Results}

In absence of indoor source outdoor particle number concentrations are significantly higher compared to parallel indoor measurements. A typical time series of outdoor and indoor concentrations is shown in figure 1.

Figure 2 demonstrates that particle size distributions indoors are shifted towards larger particles.

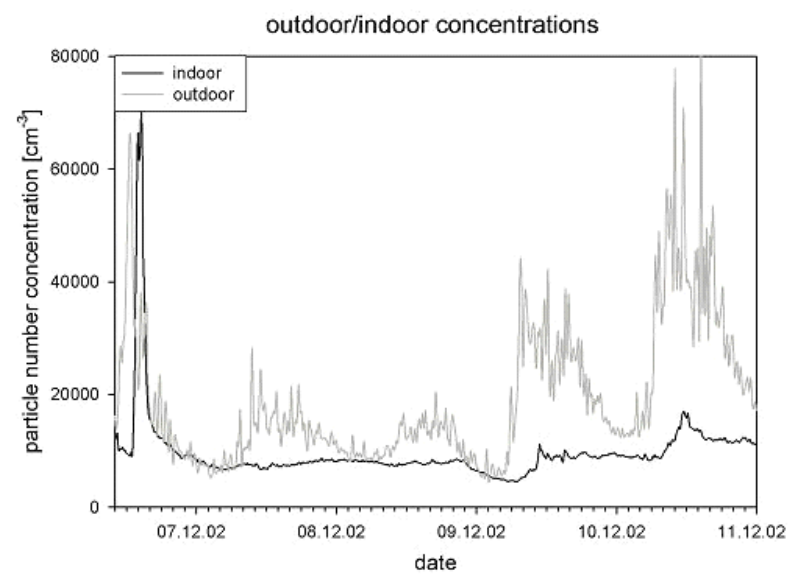

Figure 1: Indoor and outdoor total number concentrations.

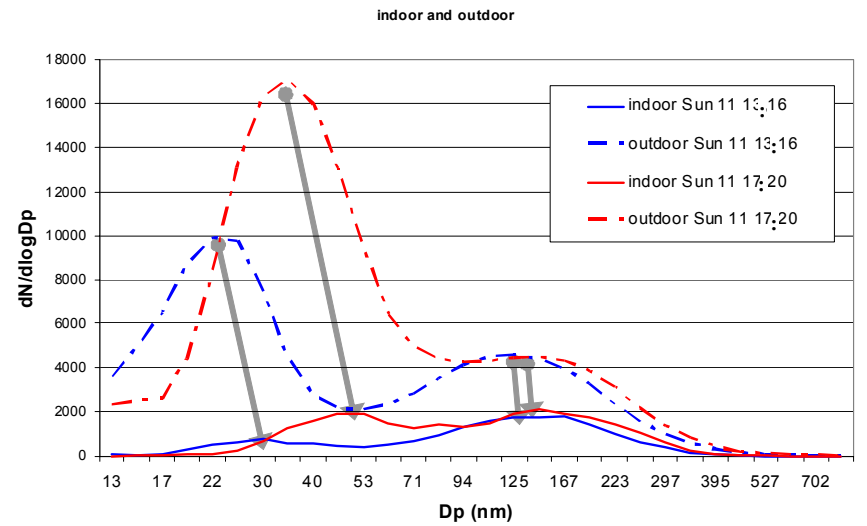

Figure 2: Simultaneously measured indoor and outdoor particle size distributions. 
Indoor and outdoor concentrations are correlated. Generally, the correlation is highest between the concentrations of indoor particles of a specific size and smaller outdoor particles. We found higher correlation coefficients for a time lag between earlier outdoor measurements and indoor measurements because outdoor particles need a specific time to penetrate into the indoor environment.

Figure 3 elucidates the time dependence of the correlation between $34 \mathrm{~nm}$ outdoor particles and indoor particles with a diameter of 108. In this example correlation coefficient is highest for a time lag of approximately $2 \mathrm{~h}$. Generally, it is the same tendency for all particle sizes: Outdoor concentrations of particles of a selected diameter exhibit the highest correlation with larger indoor particles and with a time lag which under this experimental condition was about 2 hours. It must be noted, that this time lag is more or less specific for our measurement sites. The time lag for other indoor environments depends among other things on the air exchange rate between outdoor and indoor air.

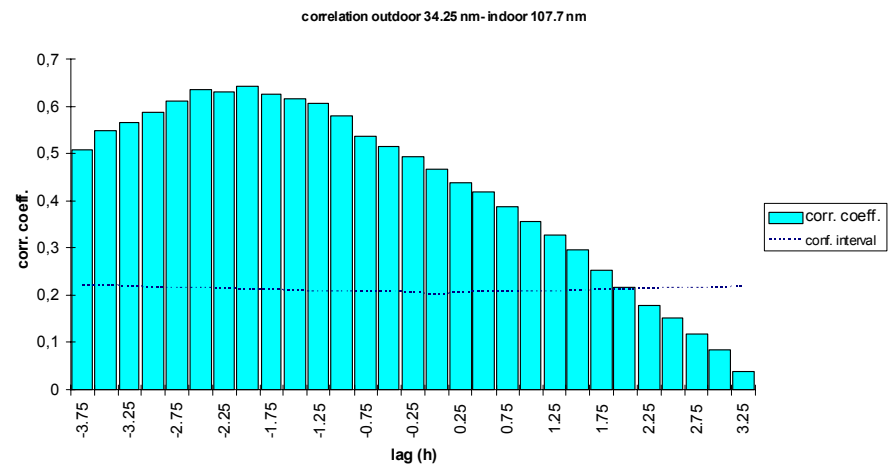

Figure 3: Correlation Coefficients of Concentrations of outdoor particles of a diameter of $34 \mathrm{~nm}$ with indoor particle concentrations $(107.7 \mathrm{~nm})$. (The lower correlation coefficients for positive times show that outdoor concentrations which are measured after the indoor concentrations do not influence the indoor concentrations or, with other words, that auto-correlation is not the basic reason for this correlation pattern.)

In studies addressing acute health effects an appropriate time lag must be added to the time lag of the health effect itself if outdoor concentrations are used as measure for the exposure of a person indoors.

Our findings demonstrate that outdoor and indoor number concentrations and particle size distribution are different. The important question for an epidemiologist is therefore:

To which share of outdoor particles humans will be really exposed indoors? In lack of actual indoor measurements average particles size distribution shifts and typical time lags may be used to derive an average function needed to 
calculate indoor exposure from outdoor measurements. Only a limited number of indoor measurements in typical homes of the study population is necessary to determine this function.

Figure 4 shows the average of about 1500 size distributions measured indoors and outdoors. The ratio between indoor and outdoor concentrations is highest for ultrafine particles.

For epidemiological studies a shielding efficiency can be calculated from such averages. This shielding efficiency is particle size dependent (Fig. 5).

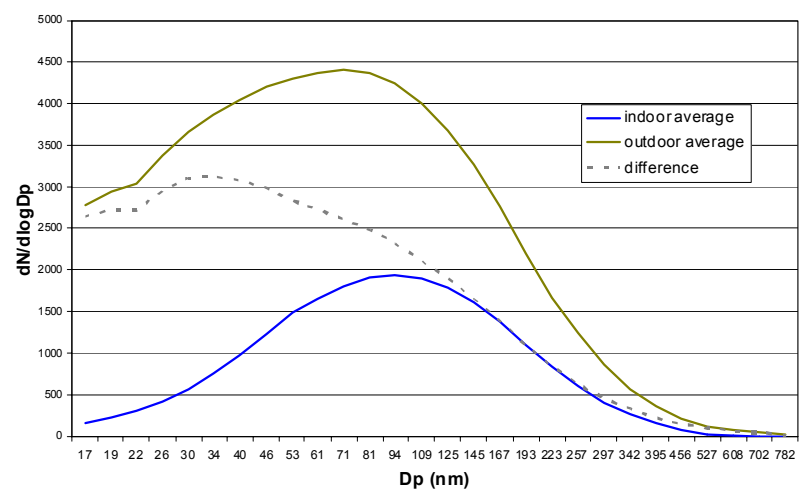

Figure 4: Averaged indoor and outdoor size distributions for sub-micrometer particles. (Data from all four seasons.)

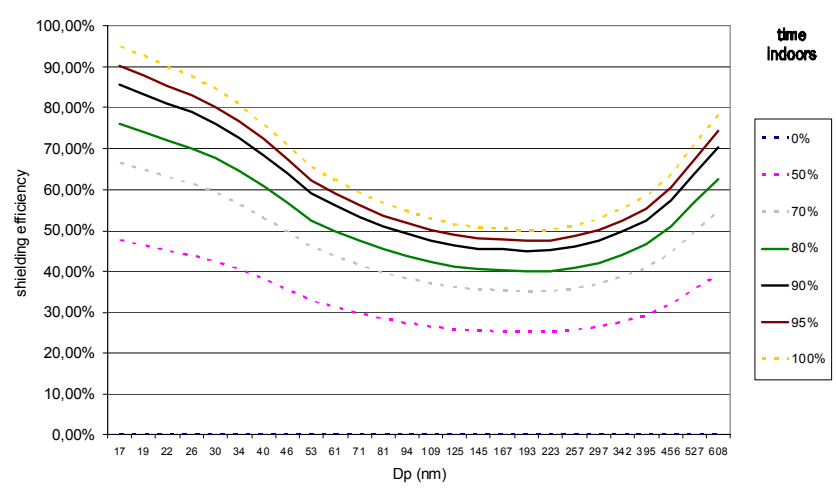

Figure 5: Exposure reduction by indoor shielding. The total shielding efficiency takes different indoor time budgets into account.

The calculated shielding efficiency can than be used to fold outdoor particle size distributions (measured earlier due to the time lag) with the appropriate curve for the time spent indoors to determine an average exposure of a population under study. If, on the other hand, only integral number or mass concentrations are of interest for a specific epidemiological study shielding efficiency curves can be integrated to calculate shielding efficiencies for such 
size ranges. Using the size distribution data, two typical size fractions of aerosol can be formed: The size range from $17 \mathrm{~nm}$ to $109 \mathrm{~nm}$ represents the ultrafine fraction of PM1. For typical indoor time budgets $(80-95 \%$ of the day indoors) $60 \%$ to $70 \%$ of outdoor ultrafine particles do not penetrate into the indoor environment. The size range from $109 \mathrm{~nm}$ to $782 \mathrm{~nm}$ corresponds to the coarser fraction of PM1. The indoor shielding efficiency for this fraction varies between $40 \%$ and $50 \%$.

\section{Conclusion}

Outdoor particles contribute to indoor particle exposure. Both indoor size distributions and concentrations are different from those measured outside. Total exposure including the time budget indoors and outdoors differs from the exposure measured outdoors.

The observed differences between indoor and outdoor exposure to particulate air pollution can be summarized by "the 3 indoor Ls":

1. LESS: The indoor environment is generally shielded against outdoor particulates, leading to lower number concentrations indoors than outdoors, if no important indoor sources are present.

2. LARGER: The indoor size distributions of particles are very different from outdoor one: The concentrations of very fine particles are decreased significantly and the concentration maxima are shifted to larger diameters with respect to outdoor particle sizes.

3. LATER: There exists a time lag in the correlation between outdoor and indoor number concentrations.

Determination of typical shielding efficiencies for the homes of a study population will help to improve exposure assessment for epidemiological studies addressing health effects caused by particulate air pollution based if real indoor measurements are not possible. If typical homes of a study population still exist this approach may even be used to reevaluate existing epidemiological studies. The knowledge of indoor-outdoor ratios of particle concentrations is necessary for a sound description of the healthy housing quality.

\section{Acknowledgements}

The authors thank Maik Schilde for technical support.

Parts of this paper have been published in Env Toxicology 21:6 (2006) 606 613. The authors thank the publisher John Wiley \& Sons, Inc. for the possibility to republish parts of the published article.

\section{References}

[1] Phalen RF. 1998. Uncertainties relating to the health effects of particulate air pollution: The EPA's particle standard. Toxicology Letters 96, 97: 263 $-267$ 
[2] Schwartz J, Dockery DW, Neas LM. 1996: Is Daily Mortality Associated Specially with Fine Particles. J Air \& Waste Managm Assoc 46: 927 - 939

[3] Murphy SA, BéruBé KA, Pooley FD, Richards RJ. 1998. The response of Lung Epithelium to Well Characterised Fine Particles. Life Sciences 19: 1789 - 1799

[4] Pope CA III, Thun MJ, Namboodiri MM, Dockery DW, Evans JS, Speizer FE, Heath CW Jr. 1995, Particulate Air Pollution as a Predictor of Mortality in a Prospective Study of. U.S. Adults, Am J Respir Crit Care Med 151: $669-674$

[5] Schwartz J, Naes LM. 2000. Fine Particles Are More Strongly Associated than Coarse Particles with Acute Respiratory Health Effects in Schoolchildren. Epidemiology 11: 6 - 10

[6] Gamble JF. 1998. PM2.5 and Mortality in Long-term Prospective Cohort Studies: Cause-Effect or Statistical Associations, Environ Health Persp 9: $535-549$

[7] Pekkanen J, Timonen KL, Ruuskanen J, Reponen A, Mirme A. 1997. Effects of Ultrafine and Fine Particles in Urban Air on Expiratory Flow among Children with Asthmatic Symptoms. Environ Res 74: 24 - 33

[8] Tiittanen P, Timonen KL, Ruuskanen J, Mirme A, Pekkanen J. 1999. Fine particulate air pollution, resuspended road dust and respiratory health among symptomatic children. Eur Respir J 13: 266 - 273

[9] Tsai FC, Smith KR, Vichit-Vadakan N, Ostro BD, Chestnut LG, Kungskulniti N. 2000. Indoor/outdoor PM10 and PM2.5 in Bangkok, Thailand. J Expo Anal Environ Epidemiol 10 (1): 15-26

[10] Dreher K, Jaskot R, Richards J, Lehmann J. Winsett D, Hoffmann A, Costa D. 1996. Acute pulmonary toxicity of site fractionated ambient air particulate matter. Am J Respir Crit Care Med 153: A15

[11] Peters A, Wichmann HE, Tuch T, Heinrich J, Heyder J. 1997. Respiratory effects are associated with the number of ultrafine particles. Am J Respir Crit Care Med 155 (4): 1376 - 83

[12] Oberdörster G, Finkelstein J, Ferin J, Godleski J, Chang LY, Gelein R, Johnston C, Crapo, JD. 1996. Ultrafine particles as a potential environmental health hazard. Studies with model particles. Chest 109 (3): $68-69$

[13] Osier M, Oberdörster G. 1997. Intratracheal inhalation vs intratracheal instillation: differences in particle effects. Fundam Appl Toxicol. 40(2): $220-227$

[14] Churg A, Stevens B, Wright JL. 1998. Comparison of the uptake of fine and ultrafine $\mathrm{TiO} 2$ in a tracheal explant system. Am J Physiol 274 L: 81 86

[15] Li XY, Brown D, Smith S, MacNee W, Donaldson K. 1999. Short-Term Inflammatory Responses Following Intratracheal Instillation of Fine and Ultrafine Carbon Black in Rats. Inhal Toxicol 11(8): 709 - 731

[16] Lundborg M, Johansson A, Lastbom L, Camner P. 1999. Ingested aggregates of ultrafine carbon particles and interferon-gamma impair rat alveolar macrophage function. Environ Res 81(4): 309-315 
[17] Stone V, Tuinman M, Vamvakopoulos JE, Shaw J, Brown D, Petterson S, Faux SP, Borm P, MacNee W, Michaelangeli F, Donaldson K. 2000. Increased calcium influx in a monocytic cell line on exposure to ultrafine carbon black. Eur Respir J 15(2): 297 - 303

[18] Wichman HE, Spix C, Tuch Th, Wölke G, Peters A, Heinrich J, Kreyling WG, Heyder J. 2000. Particulate air pollution and daily mortality in Erfurt, FRG, Part 1: Role of Particle Number and Particle Mass. Health Effects institute, Boston, MA. 98

[19] Tuch Th. Wehner B, Franck U, Wiedensohler A. 2003. Correlation between two measurement sites for ultrafine particles within one city. J Aerosol Sci 34 / 1001: 485 - 486

[20] Voigtländer J, Tuch Th, Franck U, Birmili W, Wiedensohler A. 2003. Influence of traffic on particle size distribution in a street canyon and dependence on meteorological parameters. 34 / 1001: 585 - 586

[21] Birmili W, Stratmann F, Wiedensohler A. 1999. Design of a DMA-based size spectrometer for large particle size range and stable operation. J Aerosol Sci 30 (4): 549 - 554

[22] Franck U, Herbarth O, Wehner B, Wiedensohler A, Manjarrez M. 2003. How do the Indoor Size Distributions of Airborne Submicron and Ultrafine Particles in the Absence of Significant Indoor Sources Depend on Outdoor Distributions? Indoor Air 13: 174 -181

[23] Chao CYH, Tung TCW, Burnett J. 1998. Influence of Different Indoor Activities on the Indoor Particulate Levels in Residential Buildings. Indoor Built Environ 7: 110 - 121

[24] Reinmuth F. 1996. Raumlufttechnik. Würzburg: Vogel Buchverlag

[25] Krooß J, Siemers U, Stolz P, Weis N, Clausnitzer K-D. 1997. Luftwechselraten in Wohn- und Arbeitsräumen. Gefahrstoffe Reinhaltung der Luft 57: 357 -362

[26] Ihle C 1997. Lüftung und Luftheizung, $3^{\text {rd }}$ ed., Düsseldorf: Werner Verlag

[27] Chao CYH, Tung TC 2001. An empirical model for outdoor contaminant transmission into residential buildings and experimental verification", Atm Environ, 35, 1585 - 1596

[28] Koponen IK, Asmi A, Keronen P, Puhto K, Kulmala M. 2001. Indoor air measurement campaign in Helsinki, Finland 1999 - the effect of outdoor air pollution on indoor air. Atm Environ 35: 1465 - 1477

[29] Lohmeyer G. 1992. Praktische Bauphysik. Wiesbaden: B.G. Teubner Verlag

[30] Tuch Th, Franck U, Voigtländer, J., Wiedensohler A. 2004. Changes of the Aerosol in a Street Canyon Induced by Traffic Reduction. J Aerosol Sci 35: S385-S386 